\title{
Knowledge, Attitude, and Practices of Health Personnel in Responding to the COVID-19 Pandemic in Indonesia
}

\author{
Dyah Suryani $^{1}$, Suyitno ${ }^{*}$, Maretalinia ${ }^{3}$, Elvi Juliansyah ${ }^{4}$, Vernonia Yora Saki ${ }^{5}$, Kraichat Tantrakarnapa ${ }^{6}$
}

\begin{abstract}
${ }^{1}$ Department of Nutrition, Faculty of Public Health, Universitas Ahmad Dahlan, Yogyakarta, Indonesia, 2MPHM, ASEAN Institute for Health Development, Mahidol University, Nakhon Pathom, Thailand, ${ }^{3}$ Institute for Population and Social Research, Mahidol University, Nakhon Pathom, Thailand, ${ }^{4}$ Public Health Program, STIKes Kapuas Raya, Sintang, Indonesia, ${ }^{5}$ Institute of Science and Technology Al-Kamal, Jakarta, Indonesia, ${ }^{6}$ Department of Social and Environmental Medicine, Faculty of Tropical Medicine, Mahidol University, Bangkok, Thailand
\end{abstract}

\begin{abstract}
The COVID-19 pandemic, originated in China, has spread to worldwide, including Indonesia. Until July 2021, the growth rate has been gradually increasing, and cases have been found in all 34 provinces of Indonesia. This cross-sectional study aimed to investigate the knowledge, attitude, and practices (KAP) of health personnel in the primary health care towards the COVID-19 pandemic in Indonesia using online self-report questionnaire. A total of 440 respondents contributed to this online survey. The average level of KAP were 7.7 out of 10.0, 14.3 out of 15.0 , and 31.9 out of 36.0 , respectively. There was no significant association between respondents' characteristics (sex, marital status, and age) and their KAP for all variables showed $p$-value $>0.05$. It can be concluded that the level of KAP was good, despite the respondents' characteristics that had no association with KAP.
\end{abstract}

Keywords: COVID-19, health personnel, Indonesia, knowledge distribution

\section{Introduction}

The original coronavirus originated in Wuhan, China, at the end of 2019 and was called as coronavirus disease 2019 (COVID-19).1-4 The virus had spread rapidly to more than 200 countries, and the World Health Organization (WHO) declared this disease as a global pandemic.5,6 Until July 2021, the new variant of the virus had spread rapidly to all countries worldwide. It has negatively impacted society in terms of the economy, public health, and daily life activities, and many people have become unemployed. By July 10, 2021, the number of accumulated confirmed COVID-19 cases totaled 185 million globally. ${ }^{7}$ On the same date in Indonesia, the total confirmed cases were 2,455,912, with 64,631 total deaths. ${ }^{7}$ The number of recovered cases reached 53,945, and the test cases for the whole country totaled $1,310,924$, equal to 4,790 cases per 1 million population. ${ }^{7}$ The first case in Indonesia was reported in Jakarta, the capital city of Indonesia, and the number of morbidity and mortality increased sharply. Since then, the frontline workers, including health personnel, have taken care of the COVID-19 patients.

COVID-19 has disrupted public health measures and systems throughout the world. Many health personnel had passed away due to the lack of personal protective

Correspondence*: Suyitno, MPHM, ASEAN Institute for Health Development, Mahidol University 999 Phuttamonthon 4 Road, Salaya, Nakhon Pathom 73170 Thailand. Email: senopalawija@gmail.com; Phone: +62 81325260300 equipment (PPE), the lack of awareness of the harmful nature of the disease, accidental operations, and other factors. ${ }^{8}$ To control the spread of COVID-19, public health personnel need to be strengthened. ${ }^{9}$ Some public health personnel might be carriers, and others are persons under investigation (PUI). Knowledge, attitudes, and practices (KAP) constitute important components for health personnel to care for patients with COVID-19 and PUI groups. Health personnel needs to understand the changing situation and adjust their normal behaviors to stem the COVID-19 pandemic.

Sufficient protection and prevention may prevent the spread of the virus. Providing facilities plays a crucial role in interventions and mitigation measures undertaken according to the appropriate guidelines. The COVID-19 pandemic is spreading unpredictably due to many influencing factors. It continues to cause morbidity, mortality, and normal life disturbance; it is also a burden on health systems. ${ }^{10,11}$ This survey constitutes an overall assessment of general information that could represent the Indonesian experience in responding to the COVID-19 outbreak. Assessing the KAP related to COVID-19 among health personnel would benefit the government or involved organizations in performing any intervention according to the obtained results. Moreover, recommen-

Received : May 07, 2021

Accepted : October 22, 2021

Published: November 29, 2021 
dations from health personnel would be important information to strengthen the COVID-19 response. This study aimed to determine the KAP of health personnel responding to the COVID-19 pandemic in Indonesia.

\section{Method}

A community-based cross-sectional study was conducted among health personnel in all 34 provinces in Indonesia. The data were collected in May 2020 after obtaining ethical approval from the Health Research Ethics Committee, the National Institute of Health Research and Development (Certificate of Approval No. LB.02.01/KE.330/2020). The authors used an online self-reported questionnaire (Google Form) and were distributed to respondents with a consent form. The first page of the questionnaire informed all respondents about the background and objectives of the study and provided the consent form according to ethical requirements. Respondents could withdraw anytime without giving reasons if they did not wish to participate. Completing the questionnaire would not affect their jobs; all data were kept confidential, and the results were presented in general terms.

A self-report questionnaire was used to collect the data based on the respondent's own experiences and KAP. The validity and reliability of the self-report questionnaire were tested on 30 volunteers in Yogyakarta. The respondents answered the questions in the Google Form. The values of Cronbach's alpha for the knowledge and attitude items were 0.890 and 0.823 , respectively.

The target population consisted of health personnel in primary health care in each province of Indonesia. The inclusion criteria comprised the following: 1) working in a primary health care (PHC) and 2) achieving the minimum standard of a professional in a PHC from the Ministry of Health of the Republic of Indonesia; this included doctor or primary care doctors, dentists, nurses, midwives, public health workers, sanitarians, medical laboratory technology experts, nutritionists, and pharmacists. The self-report questionnaire consisted of four sections: the general characteristics of the respondents (sex, age, marital status, education, and position), as well as the knowledge of, attitudes towards, and practices regarding the COVID-19 disease.

Based on data from the Ministry of Health of the Republic of Indonesia, the number of health personnels in PHCs is 400,908 . The following equation was used to estimate the sample size (n) (Formula 1). The equation indicated that a sample size of 384 was needed. To compensate for missing cases, the sample sizes added $10 \%$. Thus the required sample size at least 422. After data collection, the authors checked and cleaned the completed of questionnaires. Totally 440 of eligible respondents were received which more than expected for this study.

$$
\mathrm{n}=\frac{\mathrm{z}_{1-\alpha / 2}^{2} \mathrm{p}(1-\mathrm{p}) \mathrm{N}}{\mathrm{d}^{2}(\mathrm{~N}-1)+\mathrm{z}_{1-\alpha / 2}^{2} \mathrm{P}(1-\mathrm{p})}
$$

Notes: n: Minimum Sample Size, N: Population, d: Margin of Error (5\%), $\mathrm{Z}_{1-\alpha / 2}: \mathrm{Z}$ Table Score, P: Estimated Proportion

\section{Formula 1. Estimate of Sample Size for Cross-Sectional Study}

The questionnaire was distributed through social media. The sample was selected by proportional random sampling based on the province of origin.

The data were checked and cleaned for the missing information before being analyzed using statistical tests. The questionnaire consisted of general characteristics, questions about the level of knowledge (LK), the level of attitude (A), and the level of practice (using PPE (UP) and personal hygiene $(\mathrm{PH})$ ). Each questionnaire was grouped by province. The eligible questionnaires were collected online, and the cross-sectional surveys were tabulated, analyzed, and statistically interpreted. Descriptive statistics and correlation analysis were employed to determine the frequencies of each question under the variable levels of the KAP of health personnel towards COVID-19 in respect to demographic variables. The Pearson correlation was used to analyze the direction and magnitude of the correlation between each variable (LK, $\mathrm{A}$, and level of practice). The mean scores for each variable (LK, A, UP, PH) obtained concerning their characteristics were analyzed and compared using the independent sample t-test, one-way analysis of variance (ANOVA) to identify the difference between categorical independent variables and numeric dependent variables. In detail, the t-test aimed to see the differences between sex (male and female) and the mean of KAP, and the ANOVA test aimed to see the differences between marital status (single, married, and divorced) and the mean of KAP. The ANOVA test also aimed to see the differences between age groups (20-29, 30-39, 40-49, and 50-59) and the mean of KAP. The statistical software SPSS of Mahidol University, licensed version-18, was used to analyze the data.

\section{Results}

A total of 440 eligible samples were analyzed in this study. The average age was 30.4 years, with a standard deviation of 5.7. The minimum age was 22 , and the maximum age was 57 years. The majority of respondents were female $(69.8 \%)$, with $55 \%$ married, $41.4 \%$ single, and $2.3 \%$ divorced. Most graduated at the Diploma III $(51.8 \%)$; the second rank was senior high school or Diploma I and II (25.7\%), as detailed in Table 1.

Ten questions related to the COVID-19 were asked. The average score was 7.7 of 10 , with minimum and 
maximum scores of 4 and 10, respectively. More than $50 \%$ of respondents could answer correctly. However, some respondents provided wrong answers: they did not know that COVID-19 could spread from human to human $(36.1 \%)$ and lacked knowledge about the common methods to prevent the spread, like washing hands regularly $(45.5 \%)$. Health personnels who checked, provided care, delivered the patient, and cleaned the COVID-19 ward without any standard PPE could be included in the PUI group, even without symptoms $(44.8 \%)$. One interesting issue involved the emergency cases: most respondents $(81.1 \%)$ indicated that they should help patients without any PPE implementation. Health personnels were not required to apply " 5 moments of hand hygiene" in handling patients with COVID-19 because they experienced an emergency condition. The " 5 moments of hand hygiene" was a procedure issued as a guideline by the Ministry of Health of the Republic of Indonesia. The answers to the other issues raised, shown in Table 3, were at good levels (percentage of correct answers higher than 90\%). Participants achieved a mean knowledge score of $55 \%$.

Participants of this study project were asked to respond to five attitude statements. About $98 \%$ agreed that health workers must avoid touching/rubbing the eyes, nose, or mouth with potentially contaminated gloves or bare hands. Regarding the three negative attitudes in this questionnaire, the respondents had a good attitude toward responding to COVID-19 preventive measures: about $88 \%$ disagreed with working with patients of COVID-19 without PPE, $86.6 \%$ disagreed with re-using gloves for the next activity, even in urgent or emergency cases and 95.2\% disagreed with re-using surgical disposal masks. However, most had a positive attitude towards COVID-19 mitigation measures or prevention approaches, as presented in Table 2. Most health personnel had positive attitudes towards mitigating COVID-19 (more than $85 \%$ ).

Twelve statements were used to assess health personnel practices, as presented in Table 3. Health personnel did not perform many activities appropriately: they did not wear standard masks when providing services at the PHC $(10.3 \%)$, did not wear a gown $(21.9 \%)$, did not wear eyeglasses or protect their eyes when providing health services at the PHC (23.4\%), and did not wear boots $(25.9 \%)$. These manners would induce the transmission of the disease to others at the PHC or even

Table 1. General Characteristics of Respondents $(n=440)$

\begin{tabular}{llrr}
\hline Variable & Category & $\mathbf{n}$ & $\%$ \\
\hline Sex & Male & 127 & 28.9 \\
& Female & 307 & 69.8 \\
Age (year), $\mathrm{n}=440$ & 6 & 1.4 \\
Marital status & No identification & $30.4 \pm 5.7$ & $(22-57)$ \\
& Mean \pm SD (Min-Max) & 182 & 41.4 \\
& Single & 242 & 55.0 \\
& Married & 10 & 2.3 \\
Education & Divorced & 6 & 1.4 \\
& No identification & 113 & 25.7 \\
& Senior high school/Diploma I/ & 228 & 51.8 \\
& Diploma II/or equivalent & 91 & 20.6 \\
& Diploma III & 2 & 0.5 \\
& Bachelor degree & 6 & 1.4 \\
\hline
\end{tabular}

Note: $\mathrm{SD}=$ Standard Deviation

Table 2. Knowledge and Attitude of Respondents in Each Question

\begin{tabular}{|c|c|c|c|}
\hline \multicolumn{2}{|c|}{ Level of Knowledge Statement } & \multirow{2}{*}{$\frac{\text { Correct (n) }}{403}$} & \multirow{2}{*}{$\begin{array}{c}\% \\
91.6\end{array}$} \\
\hline LK1 & COVID-19 is a new disease for which there is yet to be confirmed case among humans. & & \\
\hline LK2 & COVID-19 can spread from human to human through airborne or droplet transmission. & 281 & 63.9 \\
\hline LK3 & $\begin{array}{l}\text { The people at highest risk of spreading this disease are those who intimately contact patients with COVID-19, including } \\
\text { health personnels taking care of patients with COVID-19. }\end{array}$ & 428 & 97.3 \\
\hline LK4 & The standard recommendation to prevent the spread of infection is by washing hands regularly with clean running water. & 240 & 54.5 \\
\hline LK5 & $\begin{array}{l}\text { Health personnels who check, take care of, deliver the patients, and clean the ward of COVID-19 cases without any standard PPE } \\
\text { can be included in the PUI group even without showing symptoms. }\end{array}$ & 243 & 55.2 \\
\hline LK6 & Limiting the number of health personnels in the ward when one has no direct concerns is one step of prevention. & 428 & 97.3 \\
\hline LK7 & Before taking specimens from patients with COVID-19, health personnels must take universal precautions. & 416 & 94.5 \\
\hline LK8 & Health personnels must use full PPE and standard masks when taking specimens of patients with COVID- 19 . & 407 & 92.5 \\
\hline LK9 & Before using PPE, coveralls, watches, jewelry must be removed. & 428 & 97.3 \\
\hline LK10 & $\begin{array}{l}\text { Health personnels are not required to apply " } 5 \text { moments of hand hygiene" when handling COVID-19 patients who require } \\
\text { emergency care. }\end{array}$ & 83 & 18.9 \\
\hline \multicolumn{2}{|c|}{ Level of Attitude Statement } & Agree (n) & $\%$ \\
\hline A1 & Health personnels must avoid touching/rubbing the eyes, nose, or mouth with potentially contaminated gloves or bare hands. & 431 & 98.0 \\
\hline A2 & Due to PPE limitations, health personnels are allowed to handle patients with COVID-19 without using PPE due to their responsibility. & ty. 51 & 11.6 \\
\hline A3 & In urgent conditions, gloves that have been used are allowed to be re-used. & 59 & 13.4 \\
\hline A4 & Surgical masks can be re-used until they break. & 21 & 4.8 \\
\hline A5 & When working in the COVID-19 ward, gloves must be changed for each patient. & 409 & 93.0 \\
\hline
\end{tabular}

Notes: LK = Level of Knowledge, $\mathrm{A}=$ Level of Attitude, PPE $=$ Personal Protective Equipment 
Table 3. The Practice of Using Personal Protective Equipment and Personal Hygiene of Respondents in Primary Health Care

\begin{tabular}{|c|c|c|c|c|c|c|c|}
\hline \multirow{2}{*}{\multicolumn{2}{|c|}{ Using PPE Practice Statement }} & \multicolumn{2}{|c|}{ Always } & \multicolumn{2}{|c|}{ Sometimes } & \multicolumn{2}{|c|}{ Never } \\
\hline & & \multirow{2}{*}{$\frac{n}{376}$} & \multirow{2}{*}{$\%$} & \multirow{2}{*}{$\frac{n}{39}$} & \multirow{2}{*}{$\%$} & \multirow{2}{*}{$\frac{n}{25}$} & \multirow{2}{*}{$\%$} \\
\hline UP1 & I follow the standards of prevention and control of COVID-19 infections. & & & & & & \\
\hline UP2 & $\begin{array}{l}\text { If patients are isolated, I follow transmission-based precautions, e.g., avoiding } \\
\text { direct contact with patients and exposure to droplets. }\end{array}$ & 389 & 88.4 & 24 & 5.5 & 27 & 6.2 \\
\hline UP3 & I wash my hands before and after providing health services at the PHC. & 410 & 93.2 & 21 & 4.8 & 9 & 2.1 \\
\hline UP4 & I wash my hands before and after using gloves. & 375 & 85.2 & 57 & 13.0 & 8 & 1.9 \\
\hline UP5 & I wear gloves whenever I provide health services at the PHC. & 376 & 85.5 & 50 & 11.4 & 14 & 3.2 \\
\hline UP6 & I wear a standard acceptable mask when I provide health services at the PHC. & 345 & 78.4 & 50 & 11.4 & 45 & 10.3 \\
\hline UP7 & I wear a gown when I provide health services at the PHC. & 260 & 59.1 & 84 & 19.1 & 96 & 21.9 \\
\hline UP8 & I wear glasses or eye protection when I provide health services at the PHC. & 244 & 55.5 & 93 & 21.1 & 103 & 23.4 \\
\hline UP9 & I wear (rubber) boots when I provide health services at the PHC. & 234 & 53.2 & 92 & 20.9 & 114 & 25.9 \\
\hline UP10 & I take off my (rubber) boots without touching them with my hands. & 294 & 66.8 & 86 & 19.5 & 60 & 13.7 \\
\hline UP11 & I take off my eye protection by pulling the rope from the back of my head. & 317 & 72.0 & 61 & 13.9 & 62 & 14.1 \\
\hline UP12 & $\begin{array}{l}\text { I remove the mask from the back of my head, first removing the lower strap } \\
\text { from the top of my head, then removing the upper strap from the back of the head. }\end{array}$ & 310 & 70.5 & 106 & 24.1 & 24 & 5.5 \\
\hline \multicolumn{4}{|c|}{ The Facilities Supporting COVID-19 Work Question } & \multicolumn{2}{|c|}{ Yes (n) } & \multicolumn{2}{|l|}{$\%$} \\
\hline PH1 & \multicolumn{3}{|l|}{ Are hand sanitizers/hand rubs available at your workplace during this pandemic? } & \multicolumn{2}{|r|}{414} & \multicolumn{2}{|l|}{94.1} \\
\hline $\mathrm{PH} 2$ & \multicolumn{3}{|l|}{ Do you easily wash your hands with running water and soap during this pandemic? } & \multicolumn{2}{|r|}{425} & \multicolumn{2}{|l|}{96.6} \\
\hline PH3 & \multicolumn{3}{|c|}{ Do you have hand sanitizers/hand rubs and handwashing facilities in your home during this pandemic? } & \multicolumn{2}{|r|}{387} & \multicolumn{2}{|l|}{88.0} \\
\hline $\mathrm{PH} 4$ & \multicolumn{3}{|c|}{ Do you have handwashing guides/posters in your workplace/home during this pandemic? } & & 405 & \multicolumn{2}{|l|}{92.0} \\
\hline PH5 & \multicolumn{3}{|l|}{ Is PPE available for handling COVID-19? } & & 311 & \multicolumn{2}{|l|}{70.7} \\
\hline
\end{tabular}

Notes: PPE = Personal Protective Equipment, UP = Using PPE, PH = Personal Hygiene, PHC = Primary Health Care

Table 4. The Pearson Correlation Coefficient of Knowledge, Attitude, and Practice

\begin{tabular}{lccr}
\hline Variable & Knowledge Score & Attitude Score & Practice Score \\
\hline Knowledge score & 1 & $-0.303^{* * * *}$ & -0.051 \\
Attitude score & & 1 & 0.025 \\
Practice score & & & 1 \\
\hline
\end{tabular}

Notes: ${ }^{*}$-value $<0.05$, $* *$ p-value $<0.01$, $* * *$ p-value $<0.001$

among their family members.

Five questions were asked to all participants. The first question was concerning the availability of hand sanitizers in the workplace during the COVID-19 pandemic. It was found that $5.9 \%$ of respondents indicated that they were unavailable. The accessibility to water and soap for handwashing in the workplace was $96.6 \%$, preparing hand sanitizers and handwashing at home was $88 \%$, providing guidelines of handwashing in the workplace or home was $92 \%$, and $70.7 \%$ of respondents indicated that PPE was unavailable during the COVID-19 pandemic. Details about PPE issues are presented in Table 3.

The Pearson correlation was tested to understand the correlation of each variable (ratio or interval scale only). It was found that the coefficient correlation between knowledge and attitude was -0.303 , which means that a higher level of knowledge will affect a lower attitude with a weak correlation (based on the Pearson coefficient interval). The coefficient correlation between knowledge and practice was -0.051 , which means higher knowledge will affect lower practice with a very weak correlation. The coefficient correlation between attitude and practice was 0.025 , which means higher knowledge will affect higher practice with a very low correlation. However, there was no significant correlation between knowledge $\&$ practice and attitude \& practice (Table 4 ).

No association of respondent characteristics (sex, marital status, age group) with KAP was found. This result indicated that respondents had similar knowledge levels, attitudes, and practices concerning the COVID19. The mean KAP score for each category did not differ significantly, as shown in Table 5 . The respondents reported that the most important and needed PPE were hazmat suits $(44.3 \%)$, surgical or medical-grade masks $(43.9 \%)$, boots $(27.5 \%)$, goggles $(26.3 \%)$, and other small proportions such as nurse cups $(3.9 \%)$, face shields $(5.9 \%)$, and aprons $2.3 \%)$. Fifteen percent indicated that they received proper and sufficient PPE. 
Table 5. Comparison of General Characteristics of Respondents and Mean of Knowledge, Attitude, and Practices

\begin{tabular}{|c|c|c|c|c|c|c|c|c|c|c|c|c|}
\hline \multirow{2}{*}{ Variable } & \multirow{2}{*}{ Category } & \multirow{2}{*}{$\mathbf{n}$} & \multirow{2}{*}{$\%$} & \multicolumn{3}{|c|}{ Knowledge } & \multicolumn{3}{|c|}{ Attitude } & \multicolumn{3}{|c|}{ Practice } \\
\hline & & & & Mean & SD & p-value & Mean & SD & p-value & Mean & SD & p-value \\
\hline \multicolumn{13}{|l|}{ t-test results } \\
\hline \multirow[t]{2}{*}{ Sex } & Male & 127 & 29.3 & 7.85 & 1.33 & 0.26 & 14.02 & 1.83 & 0.06 & 32.13 & 4.65 & 0.43 \\
\hline & Female & 307 & 70.7 & 7.69 & 1.41 & & 14.36 & 1.29 & & 31.76 & 4.16 & \\
\hline \multicolumn{13}{|c|}{ ANOVA test results } \\
\hline \multirow[t]{3}{*}{ Marital status } & Single & 182 & 42.1 & 7.74 & 1.26 & 0.97 & 13.29 & 2.43 & 0.60 & 31.73 & 4.31 & 0.87 \\
\hline & Married & 242 & 56.0 & 7.72 & 1.49 & & 13.25 & 2.25 & & 31.94 & 4.34 & \\
\hline & Divorced & 8 & 1.9 & 7.63 & 0.91 & & 15.00 & 0.00 & & 32.00 & 3.38 & \\
\hline \multirow[t]{4}{*}{ Age group } & $20-29$ & 265 & 63.8 & 7.65 & 1.36 & 0.283 & 14.31 & 1.44 & 0.49 & 32.05 & 4.06 & 0.14 \\
\hline & $30-39$ & 117 & 28.2 & 7.81 & 1.50 & & 14.20 & 1.55 & & 31.09 & 4.80 & \\
\hline & $40-49$ & 26 & 6.3 & 7.96 & 1.43 & & 14.62 & 0.98 & & 32.50 & 4.23 & \\
\hline & 50-59 & 7 & 1.7 & 7.00 & 0.82 & & 14.71 & 0.76 & & 33.29 & 3.64 & \\
\hline
\end{tabular}

Note: $\mathrm{SD}=$ Standard Deviation

\section{Discussion}

As COVID-19 has just emerged, constituting a relatively new disease has caused devastating effects on human life. The publication of disease information and its transmission remains limited. More scientific support is needed. This condition is similar to the study in Malaysia, 12 or other areas like China, Bangladesh, Northwest Ethiopia, and Nigeria. ${ }^{13-16}$ Most respondents had good knowledge about COVID-19 according to the average score; however, some questions might need further consideration because many indicated wrong answers. The study in Nigeria also stated the same results, which found that the levels of knowledge among health personnels were 7.1 out of 8.16 Some misunderstood COVID-19 transmission (human to human), so this requires education and knowledge dissemination about the COVID-19 features. As the current pandemic is still currently active, the responsible organizations might have to promote the campaigns of COVID-19 to all PHCs more. ${ }^{15}$ Common methods to prevent the disease from spreading, such as washing hands regularly and the awareness of PPE use for everyone in the health center, need further promotion.

Knowledge of COVID-19 among healthcare workers (HCWs) is essential. A study in India found that HCWs are important assets for building capacity and devising preparedness strategies to control the COVID-19.17 Another study conducted in South Nigeria found that most health personnel felt they were at high risk of being infected, lacked social insurance, and needed provision for PPE. 18 Any strategies to eradicate the COVID-19 will be effective if HCWs have sufficient knowledge of the virus. A study in Malaysia found low levels of knowledge in HCWs and insufficient PPE, so the mortality rate remains high. ${ }^{19}$ The study in Saudi Arabia found the interrelationship between KAP, which specifically showed that knowledge is the most important variable and could affect attitude and practice. ${ }^{20}$ Another study in Saudi Arabia also found a high level of knowledge among PHCs, but the level of anxiety was also high at the same time. 21

The respondents had good attitudes towards reducing the transmission of COVID-19, with an average score of 14.3 and minimum and maximum scores of 5 and 15 , respectively. A few were unaware of and unconcerned with the disease transmission resulting from limited PPE in some health centers. They were concerned with and had awareness about using PPE whenever they took care of patients and on the job duty. This indicated a good point of health personnel's perceptions, showing the awareness, promotion, and campaigns launched by central and locally involved organizations. In addition, the internet and social media are easily accessible. They might be factors in personnel perceiving the globally critical situation as well as the ease of transmission and harmfulness of this disease. ${ }^{22}$ The study conducted in Wuhan, China, in March 2020 and the one conducted in the Kingdom of Saudi Arabia in May 2020 stated that vaccines were still unavailable, so preventive measures are the best approach. ${ }^{4,23}$ In Indonesia, the first batch of COVID-19 vaccines from AstraZeneca arrived in March 2021 through the COVAX initiative. ${ }^{24}$ This implies much participation in the preventive measures stipulated by the Indonesian government and WHO guidelines. The attitude in terms of motivation, discipline, and leadership led to the good performance of health personnel during the COVID-19 pandemic in Indonesia. ${ }^{25}$

The health personnel did not perform in a good manner regarding many activities. They did not wear standard masks when providing services at the PHC (10.3\%), did not wear a gown $(21.9 \%)$, did not wear eyeglasses or eye protection when providing health services at the PHC 
(23.4\%), and did not wear boots $(25.9 \%)$. Their manners would induce the transmission of the disease to others at the PHC or even among their family members. This indicates that some HCWs require a greater awareness of COVID-19; therefore, more health education and health campaigns should be regularly implemented. ${ }^{23}$ The average score of practice was 31.9 , with a minimum of 19 and a maximum of 36, indicating that many health personnel did not implement appropriate practices required for COVID-19 transmission prevention. It might be due to the emergency situation, lack of PPE, and a limited number of personal hygiene facilities like hand sanitizers. This finding was important for local and central governments to consider because health personnel should serve as a role model for the general population, as reported by the study conducted in Nigeria. ${ }^{22}$

There was no association between knowledge \& practices and attitudes \& practices among the respondents. According to the governmental training, self-learning from social media, and the guidelines recommended by the Indonesian Government and other organizations, this might be the equivalent of knowledge. Interestingly, a negative association was found among the respondent's knowledge level and attitudes towards the COVID-19. One important aspect was the mindset of health personnel that needs to be focused on in more detail. Therefore, awareness campaigns should be regularly implemented.

There are many vulnerable practices, which may lead to COVID-19 transmission. One study found that the exposure of HCWs to members of the household as well as social interactions between HCWs and members tend to increase the risk of COVID-19 infection among household members. ${ }^{26}$ Concerning the COVID-19 prevention practice among HCWs, most of them decided to resign due to insufficient PPE, which causes high levels of stress and fear of transmission. ${ }^{27-30} \mathrm{HCWs}$ with direct contact with the patients and the kitchen staff mainly were found to be asymptomatic carriers of COVID-19.31-35 Another study was recommended to provide more PPE to increase the prevention practices among HCWs. ${ }^{36}$ It is reasonable to state that PPE is the most important factor in increasing protection against and preventing COVID-19 transmission. A study in the USA found the long-term care (LTC) with inadequate supplies of PPE and COVID-19 tests could be causing a high number of cases among HCWs. ${ }^{37}$ Sufficient effort from all sectors is needed to reduce mortality in the line of duty of HCWs. ${ }^{38}$ Strict regulation is one way to ensure the availability of PPE. 39

This investigation of the KAP of health personnel in Indonesia towards COVID-19 might be the first study covering the whole country. The data collection was conducted online in one month. The readiness of organizations and people, as well as the availability of hardware facilities and PPE support, might be limited in some a- reas. However, the results may benefit authorized units to set preventive strategies to control the spread of COVID-19.

\section{Conclusion and Recommendations}

In summary, this study obtained the baseline information of the KAP of Indonesian health personnel working in PHCs towards COVID-19. The findings indicate that many health personnel the lack knowledge about the disease's characteristics and transmission; they implement improper practices when taking care of patients. However, most have good attitudes concerning disease prevention. Concerning PPE requirements, HCWs need more hazmat suits, medical-grade masks, goggles, and boots to respond effectively to COVID-19. Some categories mentioned in this study might benefit the government, especially authorized units such as the central government, The Ministry of Health, and local municipalities. The results can be used for further intervention and education or training programs for health personnel.

\begin{abstract}
Abbreviations
COVID-19: coronavirus disease 2019; WHO: World Health Organization; KAP: Knowledge, Attitude, Practice; PPE: Personal Protective Equipment; PUI: Person Under Inspection; PHC: Primary Health Care; LK: Level of Knowledge; A: Attitude; UP: Using PPE; PH: Personal Hygiene; SPSS: Statistical Package for the Social Sciences; HCWs: Healthcare Workers; LTC: Long-term Care.
\end{abstract}

\section{Ethics Approval and Consent to Participate}

Ethics approval was obtained from the Health Research Ethics Committee, National Institute of Health Research and Development (Certificate of Approval No. LB.02.01/KE.330/2020). All of the respondents could refuse to participate in the study and were given an agreement form before filling in the online questionnaires.

\section{Competing Interest}

The authors declare that there are no significant competing financial, professional, or personal interests that might have affected the performance or presentation of the work described in this manuscript.

\section{Availability of Data and Materials}

The data of this study's findings are available upon reasonable request to the corresponding author. However, the data are not available to the public regarding the participants' privacy and security.

\section{Authors' Contribution}

DS and S designed and conceptualized the study, developed the instrument for collecting the data, and fixed the methodology. Other authors assisted in analyzing and interpreting the data, finding the supporting journals, cleaning the data, preparing the questionnaire, visualizing and interpreting the results, and finalizing the manuscripts. 


\section{Acknowledgment}

The authors thanked the fast response of ethical approval from the Health Research Ethics Committee, National Institute of Health Research and Development, The Ministry of Health of the Republic of Indonesia.

\section{References}

1. Tantrakarnapa K, Bhopdhornangkul B, Nakhaapakorn K. Influencing factors of COVID-19 spreading: a case study of Thailand. Journal of Public Health. 2020; 1-7.

2. Ryu S, Chun BC, of Epidemiology KS. An interim review of the epidemiological characteristics of 2019 novel coronavirus. Epidemiology and Health. 2020; 42.

3. Lone SA, Ahmad A. COVID-19 pandemic-an African perspective. Emerging Microbes \& Infections. 2020; 9 (1): 1300-8.

4. Shereen MA, Khan S, Kazmi A, Bashir N, Siddique R. COVID-19 infection: origin, transmission, and characteristics of human coronaviruses. Journal of Advanced Research. 2020; 24: 91-8.

5. Ali SA, Baloch M, Ahmed N, Ali AA, Iqbal A. The outbreak of coronavirus disease 2019 (COVID-19)—an emerging global health threat. Journal of Infection and Public Health. 2020; 13 (4): 644-6.

6. Chakraborty I, Maity P. COVID-19 outbreak: migration, effects on society, global environment and prevention. Science of the Total Environment. 2020; 728: 138882.

7. World Health Organization. WHO coronavirus (COVID-19) dashboard; 2021.

8. Mhango M, Dzobo M, Chitungo I, Dzinamarira T. COVID-19 risk factors among health workers: a rapid review. Safety and Health at Work. 2020; 11 (3): 262-5.

9. Shamasunder S, Holmes SM, Goronga T, Carrasco H, Katz E, Frankfurter R, et al. COVID-19 reveals weak health systems by design: why we must re-make global health in this historic moment. Global Public Health. 2020; 15 (7): 1083-9.

10. Bonell C, Michie S, Reicher S, West R, Bear L, Yardley L, et al. Harnessing behavioural science in public health campaigns to maintain 'social distancing'in response to the COVID-19 pandemic: key principles. Journal of Epidemiology and Community Health. 2020; 74 (8): 617-9.

11. Hennekens CH, George S, Adirim TA, Johnson H, Maki DG. The emerging pandemic of coronavirus and the urgent need for public health leadership. The American Journal of Medicine. 2020; 133 (6): 648-50.

12. Azlan AA, Hamzah MR, Sern TJ, Ayub SH, Mohamad E. Public knowledge, attitudes and practices towards COVID-19: a cross-sectional study in Malaysia. PLoS One. 2020;15 (5): e0233668.

13. Zhong B, Luo W, Li H, Zhang Q, Liu X, Li W, et al. Knowledge, attitudes, and practices towards COVID-19 among Chinese residents during the rapid rise period of the COVID-19 outbreak : a quick online cross-sectional survey. The International Journal of Biological Sciences. 2020; 16 (10): 1745-52.

14. Ferdous MZ, Islam MS, Sikder MT, Mosaddek ASM, Zegarra-Valdivia JA, Gozal D. Knowledge, attitude, and practice regarding COVID-19 outbreak in Bangladesh: an online-based cross-sectional study. PLoS One. 2020; 15 (10): e0239254.
15. Akalu Y, Ayelign B, Molla MD. Knowledge, attitude and practice towards COVID-19 among chronic disease patients at Addis Zemen Hospital, Northwest Ethiopia. Infection and Drug Resistance. 2020; 13: 1949.

16. Enenche F, Saleh A, Owoicho S, Abraham N, Jauro S, Madukaji L, et al. Knowledge, attitude, and practice among healthcare workers towards COVID-19 outbreak in Nigeria. Heliyon. 2020; 6: e05557.

17. Chatterjee PK. Community preparedness for COVID 19 and frontline health workers in Chhattisgarh. Indian Journal of Public Health. 2020; 64: 102-4.

18. Ogolodom M, AN M, Alazigha N, Erondu O, Egbe N, Golden I, et al. Knowledge, attitudes and fears of health care workers towards the corona virus disease (COVID-19) pandemic in South-South, Nigeria. Health Science Journal. 2020; 19: 1-11.

19. Nienhaus A, Hod R. COVID-19 among health workers in Germany and Malaysia. International Journal of Environmental Research and Public Health. 2020; 17 (January): 1-10.

20. Alrasheed MM, Alsugair AM, Almarzouqi HF, Alonazi GK. Assessment of knowledge, attitude, and practice of security and safety workers toward the COVID-19 Pandemic: a cross-sectional study. Frontiers in Public Health. 2021; 9: 1-13.

21. Temsah M, Huzaimi A Al, Alrabiaah A, Alamro N, Al-sohime F, Aleyadhy A, et al. Changes in healthcare workers ' knowledge, attitudes, practices, and stress during the COVID-19 pandemic. Medicine (Baltimore). 2021; 18: 1-10.

22. Reuben RC, Danladi MMA, Saleh DA, Ejembi PE. Knowledge, attitudes and practices towards COVID-19: an epidemiological survey in North-Central Nigeria. Journal of Community Health. 2021; 46 (3): 457-70.

23. Al-Hanawi MK, Angawi K, Alshareef N, Qattan A, Helmy HZ, Abudawood Y, et al. Knowledge, attitude and practice toward COVID-19 among the public in the Kingdom of Saudi Arabia: a crosssectional study. Frontiers in Public Health. 2020; 8: 217.

24. World Health Organization. Indonesia received the first batch of COVID-19 vaccines from the COVAX Facility; 2021

25. Adinugraha HH, Tanjung DS, Rismawati SD, Ma'shum AH, Arwani A, Devy HS, et al. Factors affecting health worker performance : a management evidence from midwife Sharia Hospital X in Central Java Indonesia before the Covid-19 pandemic. Korean Journal of Food \& Health Convergence. 2021; 7 (3): 13-23.

26. Yin L, Aidan W, Tan L, Jian V, Lee M, Paul M, et al. Healthcare workers in Singapore infected with COVID-19: 23 January-17 April 2020. Influenza and Other Respiratory Viruses. 2021; 15: 218-26.

27. Chu E, Lee K, Stotts R, Benjenk I, Ho G, Yamane D, et al. Hospitalbased health care worker perceptions of personal risk related to COVID-19. Journal of the American Board of Family Medicine. 2021; 34: 103-12.

28. Mohd H, Sahimi S, Iryani T, Daud M, Chan LF. Depression and suicidal ideation in a sample of Malaysian healthcare workers: a preliminary study during the COVID-19 pandemic. Frontiers in Psychiatry. 2021; 12: 1-9.

29. Peng M, Wang L, Xue Q, Yin L, Zhu B, Wang K, et al. Post-COVID19 epidemic: allostatic load among medical and nonmedical workers in China. Psychotherapy and Psychosomatics. 2021; 90 (45): 127-36. 
30. Bohlken J, Schomig F, Lemke MR, Pumberger M, Riedel-Heller SG. COVID-19 pandemic: stress experience of healthcare workers. Übersicht. 2020; 47: 190-7.

31. Ochoa-hein E, Rajme-lópez S, Leal-morán PE, Vargas-fernández AT, González-lara MF, Alberto-hernández MF, et al. Factors associated with COVID-19 and asymptomatic carriage in healthcare workers of a COVID-19 hospital. Revista de Investigación CLÍNICA. 2021; 73 (2): 65-71.

32. Cdr S, Behera V, Capt S, Kumar P, Vsm S, Jayaramachandran MJ, et al. COVID-19 in healthcare workers: a review of existing literature. Journal of Marine Medical Society. 2020; 22: S36-45.

33. Forrest CB, Xu H, Thomas LE, Webb LE, Cohen LW, Carey TS, et al. Impact of the early phase of the COVID-19 pandemic on US healthcare workers : results from the HERO Registry. Journal of General Internal Medicine. 2021; 36 (5): 1319-26.

34. Ng WT. Short communication COVID -19 : protection of workers at the workplace in Singapore. Safety and Health at Work. 2021; 12 (1): 133-5.
35. Hartuti EP, Suryani D, Edwin VA, Suyitno M. The obedience of medical personnel to using personal protective equipment in preventing the transmission of COVID-19 at a private hospital in Indonesia. Public Health of Indonesia. 2021; 7 (2): 67-74.

36. Temkin E, Worker H, Working C-S. Extremely low prevalence of asymptomatic COVID-19 among healthcare workers caring for COVID-19 patients in Israeli hospitals: a cross-sectional study. Clinical Microbiology and Infection. 2021; 27: 130.e1e130.e4.

37. Greene J, Gibson DM. Workers at long-term care facilities and their risk for severe COVID-19 illness. Preventive Medicine (Baltim). 2020; 143: 106328.

38. Xiao J, Fang M, Chen Q, He B. SARS, MERS and COVID-19 among healthcare workers : a narrative review. Journal of Infection and Public Health. 2021; 13 (6): 843-8.

39. Helmi, Hafrida, Kusniati R. Health workers ' legal protection policy to the coronavirus disease 19 (Covid-19) containment measures. FIAT JUSTISIA. 2021; 15 (1): 51-74 